\title{
ALTERAÇÕES POSTURAIS E FLEXIBILIDADE DA CADEIA POSTERIOR NAS LESÕES EM ATLETAS DE FUTEBOL DE CAMPO
}

\author{
MS. PAULO HENRIQUE ALTRAN VEIGA \\ Mestre em Ortopedia e Traumatologia pelo IOT- FMUSP e Professor Assistente II da Universidade \\ Católica de Pernambuco (Pernambuco - Brasil) \\ e-mail: paulohveiga@gmail.com.
}

ESP. CARLA RAQUEL DE MELO DAHER

Especialista em Terapia Manual, Professora Substituta do Departamento de Fisioterapia da Universidade Federal de Pernambuco-UFPE (Pernambuco - Brasil) e-mail:crdmd@hotmail.com

\author{
GRAD. MARIA FERNANDA FERNANDES MORAIS, \\ Graduada em Fisioterapia pela Universidade Católica \\ de Pernambuco (Pernambuco - Brasil) \\ e-mail:mnandam@hotmail.com
}

\begin{abstract}
RESUMO
Objetivo: Demonstrar se existe relação entre as lesões esportivas com as alterações posturais e a flexibilidade da cadeia posterior. Métodos: Foram avaliados 28 atletas de futebol de campo do sexo masculino, idade entre 17 e 20 anos, divididos em dois grupos: com lesão (GI) e sem lesão (G2). Inicialmente foi verificado peso, idade, tempo de prática e ocorrência de lesões. Em seguida foi realizada avaliação postural para verificar retrações das cadeias musculares e avaliação postural computadorizada. Resultados: Os atletas apresentaram joelhos varo, anteversão pélvica e assimetria no triângulo de Tales. O segmento corpóreo acometido mais frequente foi o tornozelo, seguido de joelhos, virilha e coxas. Conclusões: Não foi possível estabelecer relação entre as lesões no presente estudo.
\end{abstract}

PALAVRAS CHAVE: Postura; lesões esportivas; flexibilidade; futebol. 


\section{INTRODUÇÃO}

A postura pode ser apresentada como a posição que o corpo encontra-se no espaço e a relação de suas partes com a linha do centro da gravidade. Tem como conceito o estado de equilíbrio entre os ossos e músculos, desenvolvendo capacidade para proteger as demais estruturas de suporte do corpo humano de traumatismos ou deformidade progressiva, na posição ereta, sentada ou em decúbito (KENDALL , 1995; KNOPLICH, 2003; MANSOLDO, 2007; JUNIOR, 2004).

Por outro lado, o desequilíbrio muscular é definido como um desarranjo do sistema musculoesquelético. Havendo alterações posturais, o organismo precisará se reorganizar em cadeias de compensação na busca de uma resposta adaptativa a esta desarmonia. Devido à grande incidência de alterações posturais sobre os atletas, este assunto já é considerado um problema para o esporte, podendo limitar a prática da modalidade esportiva (KENDALL, 1995; MANSOLDO, 2007; JUNIOR, 2004).

A flexibilidade tem um importante papel na função neuromuscular, sendo responsável pela manutenção de uma amplitude de movimento adequada das articulações, onde os hábitos posturais podem ser determinados por essa limitação da amplitude e da extensibilidade dos músculos. Além disso, a flexibilidade facilita o aprimoramento das técnicas desportivas, gerando maior capacidade mecânica dos músculos, permitindo menor gasto energético no aproveitamento e podendo ser considerado um fator preventivo nos esportes (LIMA, 2006; ALMEIDA, 2007; GRECCO, 2007).

O futebol é o esporte mais praticado no mundo, com cerca de 400 milhões de adeptos e segundo a Federação Internacional de Futebol (FIFA), encontram-se licenciados 200 milhões de jogadores. Estudos mostram que o futebol é responsável pelo maior número de lesões esportivas no mundo, estando entre as dez mais comuns lesões esportivas entre crianças e na Europa cerca de 50 a 60 \% destas lesões são decorrentes deste esporte (STEWIEN, 2005; PALÁCIO, 2009; RIBEIRO, 2007; SILVA, 2005).

treinamento intenso e repetitivo dos atletas proporciona hipertrofia muscular e diminuição da flexibilidade, podendo levar a alterações posturais e desequilíbrio entre a musculatura agonista e antagonista nos esportistas, gerando compensações. $\bigcirc$ atleta sofre um processo de adaptação orgânica, como desvios posturais e alterações musculoesqueléticas, que resulta em efeitos deletérios para a postura, o que, adicionado a gestos específicos da modalidade e erros na técnica de execução dos movimentos pode aumentar a prevalência de lesões durante os exercícios. Os atletas só serão bem sucedidos em determinada modalidade se conseguirem atingir um ideal de adaptações características do seu esporte, bem 
como adaptações técnicas e um bom condicionamento através de um treinamento específico (RIBEIRO, 2003; SANTOS, 2007; SIMAS, 2000; LEITE, 2003; PRADO, 2004; ALVES, 2005). A exposição a fatores de risco relacionados com a idade dos atletas vem sendo demonstrados como um fator importante atualmente. A incidência de lesões tende a aumentar de acordo com a idade e atletas com idade entre 16 e 18 anos apresentam números de lesões similares aos atletas adultos. A flexibilidade é uma capacidade individual que vai se perdendo com a idade, podendo ser recuperada ou incrementada entre os 14 e 17 anos, com programas de treinamento adequados, pois após essa idade, a flexibilidade tende a diminuir progressivamente com o avançar do tempo (BERTOLLA, 2007; SILVA, 1997).

O jogador de futebol de campo geralmente assume a postura de semiflexão de quadril e joelhos, na condução da bola, corridas e passe, podendo essa semiflexão fixar-se, tornando a cadeia muscular posterior susceptível ao encurtamento. Devido a uma flexibilidade limitada e um desequilíbrio de forças estes atletas estão mais expostos a injúrias como estiramentos musculares, contusões e rupturas ligamentares. Níveis ideais de flexibilidade melhoram a amplitude articular, a força e velocidade dos movimentos durante os exercícios, tornando-os mais fáceis de serem executados e mais precisos (PRADO, 2004; BERTOLLA, 2006; SOUCHARD, 1996).

Baseado neste contexto, este estudo teve como objetivo identificar as principais alterações posturais e flexibilidade da cadeia posterior verificando se existe relação com lesões esportivas sofridas pelos atletas de futebol de campo da equipe de juniores numa instituição esportiva na cidade do Recife.

\section{PROCEDIMENTOS METODOLÓGICOS}

Este trabalho está vinculado à Universidade Católica de Pernambuco, ao Centro de Ciências Biológicas e Saúde, e ao curso de Fisioterapia. O estudo foi realizado no Clube Náutico Capibaribe, com os atletas da equipe de juniores de futebol de campo, durante o período de março a maio de 2009. A pesquisa foi feita após a aprovação do Comitê de Ética em Pesquisa da Universidade Católica de Pernambuco que emitiu parecer favorável à realização do estudo sob o número de protocolo CEP 067/2008.

O presente estudo do tipo corte transversal e descritivo, teve como amostra inicial, referente à amostra universal do time de juniores da instituição, composta de 33 atletas do sexo masculino com idade entre 17 e 20 anos. Como critérios de inclusão ficaram definidos que os sujeitos da amostra devem ser atletas de futebol de campo, contratados pela referente instituição, da categoria juniores, hígidos e que concordem em assinar o termo de consentimento livre e esclarecido. Como 
critérios de exclusão, atletas de outras instituições, praticantes de outra modalidade esportiva e presença de dor musculoesquelética que levasse o atleta a adotar uma postura antálgica, diferente de sua postura habitual.

Inicialmente foi aplicado um questionário adaptado de Baptista (1999), para caracterizar a amostra estudada quanto à idade, peso corpóreo, altura, tempo de prática esportiva, número de treinos por semana e detectar lesões sofridas. A partir deste questionário os atletas foram divididos em dois grupos: grupo I (G I) e grupo 2 (G2), onde faziam parte do GI os atletas que nunca haviam sofrido lesões relacionadas à prática do esporte e $\mathrm{G} 2$ àqueles que haviam sofrido algum tipo de lesão relacionada ao futebol.

Para análise da postura, foi utilizado o Software Fisiometer de Posturograma ${ }^{\circledR}$, versão: 2.8, onde o atleta foi posicionado em ortostatismo e em seguida colocado marcadores nos seguintes pontos anatômicos: glabela, trago direito e esquerdo, acrômio direito e esquerdo, espinha ilíaca ântero-superior direita e esquerda, ângulo inferior da escápula direita e esquerda e vértebra $L_{5}$. As imagens foram retiradas todas numa mesma sala, com um tripé, uma máquina digital Canon ${ }^{\circledR}$ modelo Power-Shot A570 de 7, I Mega Pixels e a imagem fotográfica na menor resolução (VGA), para que fosse propiciada uma imagem padronizada global do paciente sem cortes. A distância entre o apoio com o paciente e o tripé teve 3,0m e as imagens foram captadas nas vistas: anterior, posterior, perfil direito e esquerdo, onde foram retiradas duas fotos de cada vista para uma maior segurança.

Em seguida foi utilizado um protocolo para avaliar as retrações das cadeias musculares baseado na avaliação de Arruda (2009). A avaliação se consistiu com o atleta no posicionamento ortostático em que foi avaliado o alinhamento da pelve, tronco, cintura escapular e membros inferiores, e os resultados interpretados e registrados. Para avaliar a flexibilidade da cadeia posterior solicitou-se ao atleta que, com os joelhos em extensão, inclinasse a cabeça lentamente, seguida do tronco e levasse as mãos em direção ao chão, sem forçar, onde ao menor sinal de dor ou tensão incômoda o movimento era interrompido. Na análise da vista em perfil, observou-se o ângulo tíbiotársico, joelhos, ângulo coxofemoral, cuvette lombossacral (depressão sem muita profundidade na transição entre $L_{5}-S_{1}$ ), alterações das curvaturas vertebrais, posição cervical e distância mão-chão (distância entre o dedo do atleta e o solo, onde quanto maior a distância menor será a flexibilidade da cadeia posterior), verificando possíveis retrações.

A análise estatística dos dados ocorreu de forma descritiva, relacionando e comparando as lesões esportivas com alterações posturais encontradas e flexibilidade 
da cadeia posterior nos atletas. Para testar a suposição de normalidade das variáveis envolvidas no estudo foi aplicado o teste de Kolmogorov-Smirnov. Para verificar a existência de diferença entre as proporções foi utilizado o teste Qui-quadrado e o teste exato de Fisher. Para análise comparativa das médias das variáveis intergrupos foi aplicado o teste t-student. Todas as conclusões foram tomadas em nível de significância de 5\%. Os softwares utilizados foram o GraphPad Prism 3 e Microsoft Office Excel 2007.

\section{RESULTADOS}

Foi entrevistado e avaliado o total de 28 atletas, três atletas da amostra inicial estavam participando do campeonato estadual e nacional profissional não se encontrando na cidade durante a realização do estudo e dois atletas com dor musculoesquelética no momento da avaliação foram excluídos.

Após a aplicação do questionário adaptado de Baptista (1999) à amostra, os atletas foram divididos em grupos de acordo com as lesões sofridas ou não. $\bigcirc$ grupo de atletas sem lesões esportivas (GI) foi composto por 13 atletas e o grupo de atletas com lesões esportivas (G2) por 15 atletas. Os grupos apresentaram as características descritas na tabela I.

Tabela I. Caracterização da amostra quanto à idade, peso corpóreo, altura e tempo de prática desportiva no grupo de atletas sem lesões desportivas (GI) e no grupo de atletas com lesões desportivas (G2).

\begin{tabular}{llll}
\hline & Gl & G2 & \\
& Média \pm DP & Média \pm DP & *p-valor \\
\hline Idade (anos) & $\mid 7,5 \pm 0,7$ & $18,1 \pm 0,8$ & 0,0566 \\
Peso corpóreo (Kg) & $71,2 \pm 5,4$ & $71,5 \pm 6,3$ & 0,9060 \\
Altura (m) & $1,81 \pm 0,05$ & $1,76 \pm 0,06$ & 0,0705 \\
Tempo prática desportiva (meses) & $60,4 \pm 38,4$ & $69,2 \pm 40,3$ & 0,5682 \\
\hline
\end{tabular}

$\mathrm{DP}=$ desvio padrão; $\mathrm{Kg}=$ quilograma; $\mathrm{m}=$ metro.

(*) Teste t-student

Estes atletas tinham uma carga de treinamento de seis vezes por semana, de segunda a sábado, com média de dezessete horas e meia por semana, que era subdivido em: treinos técnico/tático, alongamentos (quadríceps, posterior da coxa, adutores, lombar e panturrilha) e fortalecimento (musculação uma vez na semana).

Os segmentos corporais mais acometidos pelas lesões encontradas no G2 estão expostos na tabela 2. 
Tabela 2. Distribuição dos principais tipos de lesões encontradas no grupo de atletas portadores de lesões desportivas.

\begin{tabular}{lll}
\hline Lesões & $N$ & $\%$ \\
\hline Tornozelo & 10 & $66,6^{*}$ \\
Joelho & 6 & 40,0 \\
Virilha & 3 & 20,0 \\
Coxa & 3 & 20,0 \\
\hline
\end{tabular}

$(*) p=0,0253$ quando comparada às lesões de virilha e coxa.

Teste Qui-quadrado e Teste Exato de Fisher.

Em relação à avaliação postural baseada no protocolo de Arruda (2009), não houve diferença estatisticamente significativa entre as alterações encontradas nos grupos I e 2 nos segmentos pelve e joelhos como pode ser visto nas tabelas 3 e 4 .

Tabela 3. Proporção de alterações posturais observadas na pelve no grupo de atletas sem lesões desportivas (Gl) e no grupo de atletas com lesões desportivas (G2) .

GI G2

\begin{tabular}{llllll}
$\begin{array}{l}\text { Alterações Posturais } \\
\text { Pelve }\end{array}$ & N & $\%$ & $N$ & $\%$ & p-valor* $^{*}$ \\
\hline EIAS E+Alta & 7,0 & 53,8 & 6,0 & 40,0 & 0,705 I \\
EIAS D+Alta & 2,0 & 15,3 & 4,0 & 26,6 & 0,6546 \\
EIPS+Alta que EIAS & 9,0 & 69,2 & 10,0 & 66,6 & 1,0000 \\
\hline
\end{tabular}

EIAS E = Espinha llíaca Ântero-Superior Esquerda

EIAS D = Espinha llíaca Ântero-Superior Direta

EIPS = Espinha llíaca Póstero-Superior

(*) Teste Exato de Fisher

Tabela 4. Proporção de alterações posturais observadas no alinhamento frontal dos joelhos nos grupos GI e G2.

\begin{tabular}{llllll}
\hline & Gl & & G2 & & \\
$\begin{array}{lllll}\text { Alterações Posturais } \\
\text { Joelhos }\end{array}$ & $\mathrm{N}$ & $\%$ & $\mathrm{~N}$ & $\%$ & p-valor* \\
\hline Valgo & 1,0 & 7,6 & 0,0 & 0,0 & 0,4643 \\
Varo & 12,0 & 92,3 & 15,0 & 100,0 & 0,4643 \\
\hline
\end{tabular}

(*) Teste Exato de Fisher

Em relação ao alinhamento dos joelhos no plano frontal, sendo verificada uma alta incidência de joelhos varo, onde a alteração foi encontrada em 92,3\% do GI e em 100\% dos atletas do G2. Quanto ao alinhamento dos pés não houve diferença estatisticamente significativa entre os grupos e a alteração mais encontrada, sendo vista na maioria dos jogadores em ambos os grupos, foi o calcâneo direito 
e/ou esquerdo em varo, estando presente em $76,92 \%$ do grupo I e $86,66 \%$ do grupo 2.

Quanto à flexibilidade da cadeia posterior (na manobra dedo-solo) as distâncias variaram entre I e $25 \mathrm{~cm}$. Os atletas que apresentaram menor flexibilidade (maior distância dedo-solo) faziam parte do grupo G2, onde 13,3\% dos atletas deste grupo tiveram distância mão-solo entre 21 e $25 \mathrm{~cm}$, enquanto a maior parte dos indivíduos do GI (46,6\%) ficaram com distâncias entre 6 e 10 cm. O resultado da correlação entre a flexibilidade e as lesões sofridas, mostrou-se sem significância estatística quando comparado o grupo dos atletas sem lesão com o grupo daqueles que sofreram lesão. Observou-se que 10 (77\%) atletas do GI apresentaram diminuição da flexibilidade, enquanto que 9 (60\%) atletas do G2 apresentaram a mesma característica.

No Software Fisiometer Posturograma ${ }^{\circledR}$ foram levados em consideração assimetrias de glabela, acrômios, cristas ilíacas, ângulo inferior da escápula, triângulo de Tales e posicionamento da cabeça na vista perfil. Não sendo registradas alterações na região da lombar por falta de parâmetro do posturograma quanto à normalidade da curva. Observou-se através da avaliação computadorizada que todos os atletas da amostra apresentavam algum tipo de assimetria. As relações entre as assimetrias e os grupos são encontradas na tabela 5 .

Tabela 5. Assimetrias observadas no posturograma do grupo de atletas sem lesões desportivas (GI) e no grupo de atletas com lesões desportivas (G2).

\begin{tabular}{|c|c|c|c|c|c|}
\hline \multirow{2}{*}{ Assimetrias } & \multicolumn{2}{|l|}{ GI } & \multicolumn{3}{|l|}{ G2 } \\
\hline & $\mathrm{N}$ & $\%$ & $\mathrm{~N}$ & $\%$ & p-valor* \\
\hline APC FV glabela & 9,0 & 69,2 & 12,0 & 80 & 0,6703 \\
\hline APC FV acrômio & 7,0 & 53,8 & 10,0 & 66,6 & 0,7000 \\
\hline APC FV cintura pélvica & 7,0 & 53,8 & 9,0 & 60,0 & 1,0000 \\
\hline $\begin{array}{l}\text { APC FP escápula } \\
\text { APC FP tales } \\
\text { APC PE cabeça }\end{array}$ & $\begin{array}{l}4,0 \\
12,0 \\
12,0\end{array}$ & $\begin{array}{l}30,7 \\
92,3 \\
92,3\end{array}$ & $\begin{array}{l}9,0 \\
14,0 \\
15,0\end{array}$ & $\begin{array}{l}60,0 \\
93,3 \\
100,0\end{array}$ & $\begin{array}{l}0,1513 \\
1,0000 \\
0,4643\end{array}$ \\
\hline
\end{tabular}

\section{DISCUSSÃO}

Ambos os grupos mostraram homogeneidade quanto ao peso, idade, altura e tempo de prática, não havendo diferença estatisticamente significativa entre estes.

Foi visto no presente estudo que o número de atletas no G2 foi maior que aqueles que nunca haviam sofrido lesões esportivas. A literatura mostra que o 
índice de lesões como entorses, contusões e estiramentos musculares é maior em jogadores mais jovens por uma fragilidade técnica/tática e devido ao fato de eles não posicionarem o corpo de forma correta para absorver a força ou para executar determinados tipos de habilidade (RIBEIRO, 2007; KURATA, 2007).

No que se refere às lesões, estudos mostram resultados semelhantes (SILVA, 2005; BEIRÃO, 2007). Em pesquisas realizadas com atletas de futebol, as lesões mais comuns citadas foram entorse de tornozelo e joelho, distensões e contusões. Injúrias no tornozelo foram citadas como sendo as mais comuns nestes atletas. Por outro lado, resultados diferentes foram encontrados em estudo feito com I I 0 atletas de categorias infantil e juvenil, onde a parte do corpo mais lesada foi coxa, seguida de tornozelos e joelhos (RIBEIRO, 2007). A alta incidência de lesões em membros inferiores pode se dar devido às constantes movimentações e dinâmicas que o próprio jogo exige dos atletas, afetando em especial os tornozelos (KURATA, 2007).

A anteversão pélvica pode ser vista na tabela 3 como a espinha ilíaca pósterosuperior mais alta que a espinha ilíaca ântero-superior, sendo encontrada em 69,2\% no $\mathrm{Gl}$ e em $66,6 \%$ dos atletas do $G 2$, podendo estar relacionada com a postura que o jogador assume durante treinos e jogos, o qual se posiciona em flexão de tronco, quadril e joelhos. Em estudo foi citado que este desequilíbrio contribui para formação de hiperlordose e é causado pela tensão dos flexores do quadril, contratura da musculatura lombar e fraqueza dos abdominais e glúteos (DETANICO, 2008).

Um achado importante neste estudo foi em relação ao alinhamento dos joelhos no plano frontal, sendo verificada uma alta incidência de joelhos varo, onde a alteração foi encontrada em 92,3\% do GI e em I 00\% dos atletas do G2. O fato de ser baixo o índice de alinhamento em valgo nos atletas de futebol pode ser devido a prática do futebol competitivo favorecer essa varização dos joelhos por causa dos microtraumas de repetição, impostos por treinamentos exaustivos sobre os côndilos femorais internos, em especial nos atletas jovens que encontram-se com a placa epifisária ainda aberta. Além disso, existe uma tendência dos treinadores de futebol em dar preferência aos atletas candidatos ao esporte competitivo que apresentem alinhamento em varo, devido a uma filosofia de considerá-los mais habilidosos e com maior índice técnico (ABREU, 1996).

Em estudo realizado com jogadores de futebol e hóquei, apenas 3,7\% destes atletas não apresentaram nenhum tipo de anormalidade nos pés (RIBEIRO, 2003), corroborando com os achados deste estudo, onde foi alto o índice de alterações nos pés, onde 100\% na amostra total apresentaram algum tipo de anormalidade como tuberosidade do primeiro metatarso, adução do antepé, $5^{\circ}$ dedo varo, hálux valgo, calcâneo em valgo ou varo. Foi visto uma alta incidência de atletas com calcâneo varo, onde esse fato pode ser decorrente do alto índice de joelhos em varo nestes 
indivíduos, podendo determinar disfunções nos membros inferiores influenciando esta alteração no tornozelo por mecanismos de compensação (GAMA, 2007).

No tocante à flexibilidade da cadeia posterior o número de atletas do GI com diminuição da flexibilidade foi maior do que os indivíduos que sofreram lesões (G2). Apesar de não haver diferença estatisticamente significativa entre os grupos, no presente estudo, os menores índices de flexibilidade foram relatados no $G 2$ em 13\% dos atletas, com uma distância dedo-solo entre 21 e $25 \mathrm{~cm}$.

Um ponto a ser considerado são as compensações que podem ter sido realizadas pelos atletas do GI no momento da avaliação como aumento dos ângulos tíbiotársico e coxofemoral, onde a diminuição da flexibilidade da cadeia posterior pode ser decorrente da somatória da menor contribuição destes ângulos, e também os joelhos em flexão interferem nesta mensuração, facilitando a manobra e tocando o chão (BORGES, 2006, SACCO, 2009).

Cerca de 67,8\% da amostra apresentaram diminuição na flexibilidade da cadeia posterior podendo ser justificado por estudo de revisão literária, que encontrou nos atletas de basquete, futebol e judô menor flexibilidade quando comparados com indivíduos não atletas (THACKER, 2004). O efeito de um treinamento de futebol em relação à flexibilidade das articulações do quadril, joelho e tornozelo, mostra uma redução que perdurou por 24 horas (THACKER, 2004). Outro estudo realizado com 18 jogadores de futebol profissional, usando o teste sentar e alcançar, constatou diminuição da flexibilidade da musculatura dos membros inferiores e relatou declínio progressivo da flexibilidade com a prática do futebol (SILVA, 1997).

Especialistas em medicina esportiva "acreditam" que a flexibilidade desempenhe um papel na prevenção de lesões do tipo distensões e estiramentos. Em estudo realizado com 180 jogadores de futebol submetidos a intervenções para prevenção de lesões, como a flexibilidade, encontraram correlação entre estes dois fatores. É difícil estabelecer relação da flexibilidade com lesões sofridas devido esta flexibilidade variar de um esporte para outro, onde níveis da mesma representem risco para um esporte e não para outro (THACKER, 2004). Estudos mostram não haver provas suficientes e estudos de qualidade que comprovem o alongamento como prática eficaz para a prevenção de lesões esportivas em atletas (BORGES, 2006; SACCO, 2009).

Foi possível observar através dos resultados da avaliação postural computadorizada que todos os atletas da amostra apresentaram algum tipo de assimetria. A anteriorização cervical foi encontrada em 92,3\% do grupo I e em I00\% do grupo 2. Estudo realizado com jogadores de hóquei relatou que o encurtamento da cadeia posterior, em decorrência de mecanismos compensatórios, pode estar associado com essa anteriorização (DETANICO, 2008). 
Outra assimetria importante foi o triângulo de Tales, onde 92,3\% dos atletas do Gl e 93,4\% do G2 apresentaram esta assimetria. A assimetria de pelve esteve presente em 53,8 e 60\%, respectivamente dos grupos I e 2. Estudo mostra que o ângulo de tales e o desnivelamento da cintura pélvica estão intimamente ligados aos desvios laterais da coluna (escoliose) (MANSOLDO, 2007). Estudo realizado com atletas de natação utilizando como método de avaliação postural o Software Fisiometer Posturograma $a^{\circledR}$ mostra a alta incidência de escoliose entre estes atletas, e ainda relata $94,6 \%$ dos judocas e $100 \%$ dos atletas de basquete apresentando esta alteração (MANSOLDO, 2007).

No desequilíbrio do triângulo de Tales, 64,2\% da amostra total apresentou aumento do lado esquerdo em relação ao lado contralateral, enquanto apenas 28,5\% a mesma característica do lado direito. No presente estudo não foi questionado qual a perna dominante de cada jogador, mas é sugestivo esse maior triângulo de Tales do lado esquerdo que pode ser devido no movimento do chute ocorrer uma rotação para o lado oposto e flexão do tronco, influenciando no aumento deste ângulo no lado contralateral da perna dominante, porém mais estudos precisam ser realizados.

Não foi possível estabelecer uma relação estatística entre os dados de alterações posturais e lesões sofridas. Porém, em uma análise qualitativa dos dados é possível observar a relação dos atletas que sofreram entorse do tornozelo com aqueles que tiveram lesão no joelho, onde todos apresentaram algum tipo de alteração no segmento relacionado à lesão.

Estudo realizado em 50 atletas de futsal, com idade entre 9 e 16 anos também não houve correlação direta entre possíveis alterações e lesões sofridas (RIBEIRO, 2003). Pesquisas corroboraram com os achados do presente estudo, onde não foi verificada a correlação entre desvios posturais e lesões sofridas pelos atletas de handebol e hóquei, respectivamente ${ }^{13,25}$. Este fato pode ser justificado pelas assimetrias posturais associadas às características próprias do esporte como excesso de treinamento, movimentos repetitivos e contato direto entre os atletas, e ainda às características individuais de cada sujeito que podem predispor uma ocorrência maior de lesões (DETANICO, 2008).

As lesões podem ser decorrentes ainda por métodos inadequados de treinamento, alterações estruturais que sobrecarregam mais determinadas partes do corpo ou ainda pela fraqueza muscular, tendinosa e ligamentar (KURATA, 2007).

\section{CONCLUSÕES}

Alterações posturais como joelhos varo, anteriorização da cabeça, anteversão pélvica, assimetria dos triângulos de Tales e uma diminuição na flexibilidade da 
cadeia posterior são observadas na maioria dos atletas de ambos os grupos, o que pode demonstrar, dessa forma, uma postura padrão que os jogadores de futebol apresentam, dificultando a correlação desses desequilíbrios com lesões sofridas.

A flexibilidade nestes atletas encontra-se diminuída, pois o futebol por suas características pode levar a uma rigidez crônica nos praticantes. Um programa bem elaborado de alongamentos é importante para melhorar o desempenho do atleta no esporte, em que músculos bem alongados tendem a aumentar a eficiência e diminuir o gasto energético no movimento.

Mais estudos precisam ser realizados para verificar se o uso da perna dominante durante o movimento de chute tem relação com a alta incidência de desvios laterais na coluna nos atletas de futebol de campo, verificando se essa relação implica em causa e efeito.

A não correlação entre as variáveis deste estudo pode ainda ser decorrente de um número pequeno de participantes, que se encontra abaixo das amostras apresentadas por estudos semelhantes, e isto pode ter influenciado e mascarado resultados.

Postural alterations and flexibility of the posterior chain in soccer's injuries

ABSTRACT: Purpose: To determine whether a relationship exists between sports injuries with postural changes and flexibility of the posterior chain. Methods: A total of 28 soccer players in the field of male, aged between 17 and 20 years, divided into two groups: lesion (GI) and without injury (G2). It was initially established weight, age, practice time and occurrence of injuries. Next postural assessment was performed to verify retraction of the muscle and postural assessment computerized. Results: The athletes had knee varus, anterior pelvic tilt and asymmetry in the triangle of Tales. The body segment was the most common ankle, followed by knees, groin and thighs. Conclusions: Unable to establish the relationship between the lesions in this study.

KEY WORDS: Posture; sporting injuries; flexibility; soccer.

\section{Cambios posturales y flexibilidad de cadena posterior en lesiones en atletas de fútbol}

RESUMEN: Objetivo: Determinar si existe relación entre las lesiones deportivas con los cambios de postura y la flexibilidad de la cadena posterior. Métodos: Un total de 28 jugadores de fútbol, de edades entre 17 y 20 años, en dos grupos: las lesiones (Gl), y sin perjuicio (G2). Se estableció el peso, edad, tiempo de práctica y la aparición de lesiones. Siguiente evaluación postural se realizó para comprobar la retracción de los músculos y la evaluación postural computarizado. Resultados: Los atletas había varo de la rodilla, la inclinación pélvica anterior y la asimetría en el triángulo de cuentos. El segmento del cuerpo era el tobillo más común, seguida por las rodillas, la ingle y los muslos. Conclusiones: No se puede establecer la relación entre las lesiones en este estudio.

PALABRAS CLAVE: Postura; flexibilidad; lesiones deportivas; fútbol. 


\section{REFERÊNCIAS}

ABREU, A. V; BARBOSA, J. R. P; COELHO, F. J. P. Alinhamento do joelho no plano frontal dos 12 aos 17 anos. Revista Brasileira de Ortopedia, São Paulo, v.3 I(I), p. 83-88, jan., 1996.

ALMEIDA, T. T; JABUR, N. M. Mitos e verdades sobre flexibilidade: reflexos sobre o treinamento de flexibilidade na saúde dos seres humanos. Motricidade, Vila Real, v. 3(I), p. 337-344, jun., 2007.

ALVES, L. S. Análise postural em atletas de judô da equipe da Unisul. 2005. 236 f. Dissertação (graduação) - Curso de Educação Física, Departamento de Educação Física, USSC, Tubarão, 2005.

ARRUDA, M. F. Análise postural computadorizada de alterações musculoesqueléticas decorrentes do sobrepeso em escolares. Motriz, Rio Claro, v. I 5(I ), I 43-I 50, jan./mar., 2009.

BAPTISTA, C. A; FILHO, J. A; ANDRADE, B. J. Exame Clínico geral pré-participação. São Paulo: Atheneu, 1999. p. 5I-58.

BEIRÃO, M. E; MARQUES, T. A. R. Estudo dos fatores desencadeantes do entorse do tornozelo em jogadores de futebol e elaboração de um programa de fisioterapia preventiva. Revista de Pesquisa e Extensão em Saúde, Criciúma, v. 3(1), p. 1-7, jan./dez., 2007.

BERTOLLA, F. et al. Efeito de um programa de treinamento utilizando o método pilates na flexibilidade de atletas juvenis de futsal. Revista Brasileira de Medicina do Esporte. São Paulo, V. I3(4), p. 222-226, jul./ago., 2007.

BORGES, B. L. A. Flexibilidade de atletas de basquetebol submetidos à postura "em pé com inclinação anterior" do método de Reeducação Postural Global (RPG). Revista Brasileira de Ciências do Movimento, Brasília, v. I4(4), p. 39-46, out./dez., 2006.

DETANICO, D. et al. Alterações posturais, desconforto corporal (dor) e lesões em atletas das seleções brasileiras de hóquei sobre a grama. Revista de Educação Física, Rio de Janeiro, v. 1 9(3), p. 423-430, jul./set., 2008.

GAMA, A. E. F. et al. Deformidades em valgo e varo de joelhos alteram a cinesiologia dos membros inferiores. In: X ENCONTRO DE INICIAÇÃO À DOCÊNCIA DA UFPB, 9- I I . 2007, Paraíba. Anais... Paraíba: 2007. v. I, p 40-40.

GRECCO, L. H. et al. Avaliação das formas de prevenção da pubalgia em atletas de alto nível - uma revisão bibliográfica. ConScientiae Saúde, São Paulo, v. 6(2), p. 279-285, ago., 2007.

JUNIOR, J. N; PASTRE, C. M; MONTEIRO, H. L. Alterações posturais em atletas de sexo masculino que participaram de provas de potência muscular em competições internacionais. Revista Brasileira de Medicina do Esporte, São Paulo, v. I0(3), p. 195-198, mai./jun., 2004. 
KENDALL, F. P.; MCCREARY, E. K.; PROVANCE, P. G. Músculos, provas e funções. 4. ed. São Paulo: Manole, 1995.

KNOPLICH, J. Enfermidades da coluna vertebral: uma visão clínica e fisioterápica. 3. ed. São Paulo: Robe Editorial, 2003.

KURATA, D. M; JUNIOR, J. M; NOWOTNY, JP. Incidência de lesões em atletas praticantes de Futsal. Revista de Iniciação Científica CESUMAR, Maringá, v. 09( I), p. 45-5I, jan./jun., 2007.

LEITE, C. B. S; NETO, F. F. C. Incidência de lesões traumato-ortopédicas no futebol de campo feminino e sua relação com alterações posturais. Revista Digital, Buenos Aires, v. 9(6I), jun. 2003. Disponível em: http://www.efdeportes.com/efd6 I/futebol.htm. Acesso em 27 jun. 2010.

LIMA, M. A; SILVA, V. F. Correlação entre existência de força e flexibilidade dos músculos posteriores da coxa de desportistas amadores de futebol de campo. Fit Perf Jounal, Rio de Janeiro, v.5(5), p. 376-382, set./out., 2006.

MANSOLDO, A. C; NOBRE, D.P.A. Avaliação postural em nadadores federados praticantes do nado borboleta nas provas de 100 e 200 metros. O Mundo da Saúde, São Paulo,v. 31 (4), p. 5। I-520, out./dez., 2007.

PALÁCIO, E. P; CANDELORO, B. M; LOPES, A. A. Lesões nos jogadores de futebol profissional do Marília Atlético Clube: estudo de coorte histórico do Campeonato Brasileiro de 2003 a 2005. Revista Brasileira de Medicina do Esporte, São Paulo, v. I 5 ( I), p. 3 I-35, jan./fev., 2009.

PRADO, A. L. C. O método iso-stretching na otimização das aptidões para a prática do futebol de campo. Saúde, Santa Maria, v. 30(I-2), p. 57-64, jun./ago., 2004.

RIBEIRO, C. Z. P. et al. Relação entre alterações posturais e lesões do aparelho locomotor em atletas de futebol de salão. Revista Brasileira de Medicina do Esporte, São Paulo, v. 9(2), p. 91-97, mar./abr., 2003.

RIBEIRO, R. N. et al. Prevalência de lesões no futebol em atletas jovens: estudo comparativo entre diferentes categorias. Revista Brasileira de Educação Física e Esporte, São Paulo, v. 2 I (3), p. I89-94, jul./set., 2007.

SACCO, I. C. N. et al. A influência da ocupação profissional na flexibilidade global e nas amplitudes angulares dos membros inferiores e da lombar. Revista Brasileira de Cineantropometria e Desempenho Humano, Florianópolis, v. I I ( ), p. 5I-58, jan./mar., 2009.

SANTOS, S. G. et al.. Relação entre alterações posturais, prevalência de lesões e magnitudes de impactos nos membros inferiores em atletas de handebol. Fit Perf Journal, Rio de Janeiro, v. 6(6), p. 388-393, nov./dez., 2007. 
SILVA, A. A. et al. Fisioterapia esportiva: prevenção e reabilitação de lesões esportivas em atletas do América Futebol Clube. In: $8^{\circ}$ ENCONTRO DE EXTENSÃO DA UFMG, 22. 2005, Belo Horizonte. Anais... Belo Horizonte: UFMG, 2005, v1, p. 4-8.

SILVA, P. R. S. et al. Avaliação funcional multivariada em jogadores de futebol profissional - uma metanálise. Acta Fisiátrica, São Paulo, v. 4(2), p. 65-8I, ago., 1997.

SIMAS, J. P. N; MELO, S. I.L. Padrão postural de bailarinas clássicas. Revista de Educação Física, Rio de Janeiro, v. I I(I), p. 5I-57, jan./mar., 2000.

SOUCHARD, P. E. O stretching global ativo: a reeducação postural global a serviço do esporte. I. ed. São Paulo: Manole, 1996.

STEWIEN, E. T. M; CAMARGO, O. P. A. Ocorrência de entorse e lesões do joelho em jogadores de futebol da cidade de Manaus, Amazonas. Acta Ortopédica Brasileira, São Paulo, v. 13(3), p. I4I- | 46, maio/jun., 2005.

THACKER, S. B. et al. The impact of stretching on sports injury risk: a systematic review of the literature. Am J Sports Med, Chicago, v. 36(3), p. 37I-378, abr., 2004.

Recebido: 04 set. 2010 Aprovado: 17 out. 2010

Endereço para correspondência: Paulo Henrique Altran Veiga Rua José de Holanda 510, bloco B apto 602, Bairro Torre, Pernambuco - Brasil, CEP - 507 I0- I 40 